OPEN ACCESS

Edited by:

Jinghui Fang,

Yellow Sea Fisheries Research Institute (CAFS), China

Reviewed by: Shijian Fu,

Chongqing Normal University, China Raine Kortet,

University of Eastern Finland, Finland

*Correspondence: Fang Wang wangfang249@ouc.edu.cn

Specialty section: This article was submitted to Marine Fisheries, Aquaculture

and Living Resources,

a section of the journal

Frontiers in Marine Science

Received: 21 September 2020 Accepted: 30 October 2020 Published: 01 December 2020

Citation:

Liang Q, Su X, Wang F, Zhu B and He M (2020) The Developmental

Plasticity of Boldness and Aggressiveness in Juvenile and Adult Swimming Crab (Portunus trituberculatus).

Front. Mar. Sci. 7:608565. doi: 10.3389/fmars.2020.608565

\section{The Developmental Plasticity of Boldness and Aggressiveness in Juvenile and Adult Swimming Crab (Portunus trituberculatus)}

\author{
Qihang Liang ${ }^{1,2}$, Xianpeng Su ${ }^{1,2}$, Fang Wang ${ }^{1,2 *}$, Baishan Zhu ${ }^{1,2}$ and Mingdi He ${ }^{1,2}$ \\ ${ }^{1}$ Key Laboratory of Mariculture, Ministry of Education, Ocean University of China, Qingdao, China, ${ }^{2}$ Function Laboratory \\ for Marine Fisheries Science and Food Production Processes, Qingdao National Laboratory for Marine Science \\ and Technology, Qingdao, China
}

Boldness and aggressiveness are crucial behavioral traits in the field of animal personality, and both have important ecological and evolutionary significance. As swimming crabs (Portunus trituberculatus) are aggressive, their production is affected; thus, it is important to study their behavior. To assess the relationship between boldness and aggressiveness of male $P$. trituberculatus and the differences between their different life stages, we determined the individual differences in these two traits in juvenile and adult crabs under laboratory conditions. Based on the k-means cluster analysis, boldness of crabs is classified according to their rush to adventure, and aggressiveness of crabs is classified according to their aggressive behavior toward conspecifics. The results show that the personality classification of juvenile and adult crabs was consistent. Boldness was divided into three levels: bold, middle, and shy. Aggressiveness was divided into two levels: aggressiveness and non-aggressiveness. The personality of juveniles and adults $P$. trituberculatus males was significantly different; juveniles presented higher aggressiveness and lower boldness than adults. Additionally, a significant positive correlation between boldness and aggressiveness of adult crabs was verified $(P=0.001, \rho=0.271)$. However, this correlation in juvenile crabs was not significant $(P=0.702, \rho=0.042)$. These preliminary results indicate that the personality of $P$. trituberculatus males has developmental plasticity and adults have the boldness-aggressiveness behavioral syndrome.

Keywords: animal personality, boldness, aggressiveness, trade-offs, developmental plasticity, behavioral syndrome

\section{INTRODUCTION}

Animal personality refers to the consistent individual differences in behavior across time and context (Réale et al., 2007; Biro and Stamps, 2008; Dingemanse et al., 2010). Studies have shown that mammals (Réale et al., 2009), birds (Groothuis and Carere, 2005), fish (Wilson and Stevens, 2005; Ariyomo and Watt, 2012), arthropods (Reaney and Backwell, 2007; Mowles et al., 2012; Toscano et al., 2013; Bridger et al., 2015; Belgrad et al., 2017), amphibians (Sih et al., 2003), and cephalopods 
(Sinn et al., 2008) exhibit consistent individual differences in behavioral traits, which are expressed in specific situations (Réale et al., 2000).

Boldness and aggressiveness are two personality traits that have received increased attention (Wolf et al., 2007; Ariyomo and Watt, 2012), as these traits affect the interactions between preys and predators (Coleman and Wilson, 1998), individuals, and conspecifics (Su et al., 2019). Boldness behavior refers to the tendency of individuals to take risks and explore new environments (Wilson and Godin, 2009). It is the basis for the study of animal personality and is common in natural populations (Wilson et al., 1994). Aggressive behavior is a key component of both inter- and intra-species competition; it may be crucial to obtain resources such as spouses, food, and territory, and to establish a dominance hierarchy in social populations (Norton and Bally-Cuif, 2012). There are several previous studies on boldness and aggressiveness of aquatic animals. For example, the repeatable behaviors across time and boldnessreflecting behavioral traits have been verified in the noble crayfish Astacus astacus (Vainikka et al., 2011) and juvenile brown trout Salmo trutta (Kortet et al., 2014), respectively. The juvenile pumpkinseed sunfish (Lepomis gibbosus) exhibits boldness in both foraging and predation-risk environments (Coleman and Wilson, 1998) and the bold male fiddler crab (Uca mjoebergi) is also highly aggressive, bold males fight to gain new territory, while shy males avoid fights by evicting females or occupying empty zone (Reaney and Backwell, 2007). In addition, boldness and aggressiveness are usually related to the reproductive success rate of animals. For example, bold and aggressive male zebrafish (Danio rerio) individuals have a higher reproductive success rate than the shy and less aggressive individuals. In addition, a female zebrafish paired with a bold individual has a higher egg fertilization rate (Ariyomo and Watt, 2012). However, overly bold or aggressive water striders (Aquarius remigis) (Sih and Watters, 2005) and hermit crabs (Pagurus bernhardus) (Bridger et al., 2015) have reduced reproductive success rate, because when extremely aggressive males are present, females are completely inactive and spend most of their time in waters where they rarely mate, indicating that extreme boldness and aggressiveness can be a disadvantage.

The behavioral syndrome is the correlation of behavioral traits within a given context or in different contexts (Bell and Stamps, 2004; Sih et al., 2004b), which helps to explain individual differences in behavior in the population (Norton and BallyCuif, 2012). Studies have found that boldness of three-spined sticklebacks (Gasterosteus aculeatus) (Huntingford, 1976) and Chinese mitten males (Eriocheir sinensis) (Brodin and Drotz, 2014) are, respectively, positively correlated with aggressiveness and activity; in low-risk situations, boldness and aggressiveness of the hermit crabs (Portunus bernhardus) are significantly positively correlated, but in high-risk situations, such correlation is not significant (Mowles et al., 2012). Animals adjust their behavior according to changes in environmental conditions to adapt to the context (Dirienzo et al., 2012; Vetter et al., 2016). Furthermore, studies have demonstrated that behavioral syndrome also changes in animals throughout ontogeny. For example, the boldness of juvenile guinea pigs (Cavia aperea) is related to their resting metabolic rate, whereas this correlation does not occur in adults; however, there is a significant correlation between boldness and exploration (Guenther et al., 2014). Boldness has a negative impact on the viability of juvenile male largemouth bass (Micropterus salmoides) but has a positive impact on the reproductive success rate of adult bass males (Ballew et al., 2017). Currently, research on the personality of crustacean mainly focuses on a specific life stage, especially the adult stage, ignoring the changes in personality through the animal's life stages (developmental plasticity).

The swimming crab (Portunus trituberculatus) has a fierce and aggressive personality, which significantly affects its pond production. There is limited research on the personality of $P$. trituberculatus. In the present study, we hypothesized that adult $P$. trituberculatus males showed higher levels of boldness and aggressiveness than juveniles, and these behaviors are significantly correlated, indicating a boldness-aggressiveness syndrome. To verify these hypotheses, we measured these two personality traits in juvenile and adult $P$. trituberculatus males. Each individual was studied only once for their behaviors. Individuals with similar personality were classified into the same group through $\mathrm{k}$-means cluster analysis (Yang et al., 2020). Thereafter, individual differences in personality between group levels in juvenile and adult crabs were assessed, and behavioral correlation was measured and analyzed to estimate whether the personality of $P$. trituberculatus males is consistent with developmental plasticity.

\section{MATERIALS AND METHODS}

\section{Animal Collection and Maintenance}

This experiment was conducted from June to September 2019 at the Key Laboratory of Mariculture, Ministry of Education, Ocean University of China, Qingdao, China. Only males were studied in this experiment. Personality test on juvenile crabs was lasted from June to July, and the subjects were transported to the laboratory in June. Personality test on adult crabs was conducted from August to September and the subjects were transported to the laboratory in August. During the transportation period, the seawater temperature was maintained at $24 \pm 1^{\circ} \mathrm{C}$ and dissolved oxygen was maintained above 7 to ensure that environment condition did not cause stress response to crabs. Juvenile (carapace width: $\mathrm{CW}=28.87 \pm 5.26 \mathrm{~mm}$, mean $\pm \mathrm{SD}, n=84$ ) and adult (carapace width: $\mathrm{CW}=99.77 \pm 5.71 \mathrm{~mm}$, mean $\pm \mathrm{SD}$, $n=153) P$. trituberculatus males (rearing size: $700-1,000 \mathrm{ind} / \mathrm{kg}$, rearing density: $2 \times 10^{4}-3 \times 10^{4} \mathrm{ind} / \mathrm{hm}^{2}$ ) were collected from the aquaculture facility in Jiao Nan (Qingdao, Shandong, china). Each crab was acclimatized in separate, continuously aerated aquariums $\left(45 \times 30 \times 30 \mathrm{~cm}, 40.5 \mathrm{~L}\right.$; filtered seawater $24 \pm 1^{\circ} \mathrm{C}$, $30 \%$ salinity, and 12:12 L:D photoperiod) for 2 weeks. Crabs were fed ad libitum (at 18:00 every day) with sufficient Manila clams (Ruditapes philippinarum) that were purchased from the local market. Residual food was removed, and one-third of the seawater in the aquariums were changed at 07:00 every day. Only healthy $P$. trituberculatus males in the intermolt stage with 
integral appendages were selected for the experiment. Juvenile and adult crabs were tested in a randomized order.

\section{Boldness Assessment}

P. trituberculatus prefers dim light but avoids intense light. Thus, the shelter experiment was used to test boldness of P. trituberculatus males (Yoshida et al., 2005; Brown et al., 2007). The boldness behavior capture system included an infrared camera (HIKVISION, DS-2CD7A27FWD/F-LZ(S), wavelength $=850 \mathrm{~nm}$ ), a monitor (PHILLIP, 233i, China), an opaque aquarium (Juveniles: $40 \times 25 \times 20 \mathrm{~cm}, 20 \mathrm{~L}$; Adults: diameter $=60 \mathrm{~cm}$, height $=50 \mathrm{~cm}, 141.3 \mathrm{~L}$ ), a shelter with trapdoor (Juveniles: $8 \times 6 \times 6 \mathrm{~cm}$; Adults: $30 \times 20 \times 20$ $\mathrm{cm})$, storage, and an exchanger. There were eight sets of boldness behavior capture system in which the experiments were conducted simultaneously. The infrared cameras were fixed $0.7 \mathrm{~m}$ above the aquarium; the filtered seawater $\left(24 \pm 1^{\circ} \mathrm{C}\right.$ and salinity $30 \%$ ) depth was maintained at $40 \mathrm{~cm}$ during the experiment. The photoperiod was $12 \mathrm{~h}$ light: $12 \mathrm{~h}$ dark. Filtered seawater was continuously aerated during the experiment to prevent hypoxia.

All crabs were deprived of food for $24 \mathrm{~h}$ before the experiment. The trial was performed at 08:00 in an undisturbed environment. During the experiment, the crabs were placed individually in the shelter to acclimatize for $10 \mathrm{~min}$, and then the trapdoor was gently opened. The first time that the crab left the shelter and appeared outside the shelter was recorded (Toscano et al., 2013; Fu et al., 2015). If the crab had not emerged from the shelter after $24 \mathrm{~h}$, we considered $24 \mathrm{~h}$ as the time taken by the crab to leave the shelter. The seawater in the aquarium was replaced after each test. In these tests, boldness was measured as $24 \mathrm{~h}$ (the maximum time after which the crab left the shelter) minus the time it left the shelter for the first time (the time, in hours, in which the crab stayed outside for more than $10 \mathrm{~s}$ continuously). Thus, the time crabs left the shelter for the first time was inversely proportional to boldness (Cote et al., 2010; Brodin and Drotz, 2014). According to the k-means cluster analysis (Yang et al., 2020), boldness of both juvenile and adult crabs was divided into three levels: bold, middle, and shy.

\section{Aggressiveness Assessment}

The mirror test was used to assess aggressiveness (Gerlai, 2003; Moretz et al., 2007). Each crab was tested for aggressiveness $24 \mathrm{~h}$ after each crab had been tested for boldness. The aggressiveness behavior capture system included an infrared camera (HIKVISION, DS-2CD864, wavelength $=850 \mathrm{~nm}$ ), a monitor (PHILLIP, 233i, China), an opaque aquarium (Juveniles: $40 \times 25 \times 20 \mathrm{~cm}, 20 \mathrm{~L}$; Adults: diameter $=60 \mathrm{~cm}$, height $=50$ $\mathrm{cm}, 141.3 \mathrm{~L}$ ), a mirror (Juvenile: $30 \times 20 \mathrm{~cm}$; Adult: $58 \times 20$ $\mathrm{cm}$ ), a storage, and an exchanger. There were eight sets of aggressiveness behavior capture system in which the experiments were conducted simultaneously. The mirror was placed inclined vertically $\left(22.5^{\circ}\right)$ so that the mirror image would appear closer to the crabs when they swam to the mirror. The infrared cameras were fixed $0.7 \mathrm{~m}$ above the aquarium, and the filtered seawater $\left(24 \pm 1^{\circ} \mathrm{C}\right.$ and salinity $30 \%$ ) depth was maintained at $20 \mathrm{~cm}$ during the experiment. Photoperiod was the same as that used in the boldness trials.
Initially, a crab was placed in the center of the aquarium to acclimatize for $10 \mathrm{~min}$, and then, we gently removed the plastic board to exposes the mirror to the crab. Aggressive interactions (Table 1) performed by a crab toward its mirror image were recorded for up to $2 \mathrm{~h}$ (Dunham et al., 1986) using an infrared camera. Previous studies have validated this test and showed that these interactions are similar to those seen against a "real" opponent (Ariyomo and Watt, 2012). Crabs were tested individually. During the experiment, the surrounding environment was quiet, and the seawater in the aquarium was replaced after each experiment. Aggressiveness was measured based on the number of aggressive interactions. According to the k-means cluster analysis (Yang et al., 2020), aggressiveness was divided into two levels: aggressiveness (the most aggressive males were identified as those with the highest number of aggressive interactions) and non-aggressiveness (the least aggressive males had the least number of aggressive interactions).

\section{Statistical Analysis}

All data analyses were performed using SPSS Statistics 25 (IBM, Armonk, NY, United States). Correlations between boldness and aggressiveness were calculated using Spearman rank nonparametric correlations. The differences in the three levels of boldness were analyzed using the Kruskal-Wallis $H$ test (twotailed). Differences between juvenile and adult crabs in boldness and aggressiveness, the differences in aggressiveness, and the differences of crabs in the same size (juvenile or adult) in different personality levels were compared using the Mann-Whitney $U$ test (two-tailed). For all tests; $P$-values $<0.05$ were considered statistically significant.

\section{RESULTS}

\section{Boldness}

Boldness was divided into three levels: bold, middle, and shy. There were significant differences between $P$. trituberculatus males in the bold, middle, and shy groups of boldness (Figure 1A). In addition, adult crabs were significantly bolder than juvenile crabs $(P<0.01$, Figure 2). Bold juvenile and adult crabs represented approximately 42 and $53 \%$ of the individuals, respectively, thus, the number of bold adults was significantly higher than the number of bold juveniles and from juvenile to adult, the proportion of bold crabs increased. Middle juveniles and adults represented approximately 30 and $40 \%$ of the individuals, respectively. Shy juveniles and adults represented approximately 28 and $7 \%$ of the individuals, respectively, the proportion of shy crabs decreased. The interquartile range (IQR), which represents the dispersion of each variable, of juvenile crabs regarding boldness, was approximately sixfold higher than that of adult crabs (Table 2), indicating that the boldness of juvenile crabs was more dispersed than adult crabs (Figures 3C,D).

\section{Aggressiveness}

Aggressiveness was divided into two levels: aggressiveness and non-aggressiveness. There was a significant difference between the aggressive and non-aggressive groups of 
TABLE 1 | Aggressive interaction description.

\section{Aggressive interaction}

Chela extend

Chela present

Keeping

\section{Description}

The crab holds one or both chelipeds forward and parallels to the substrate

The crab holds one or both chelipeds forward with the chela in contact with the mirror

The crab keeps one or both chelipeds forward and freezing
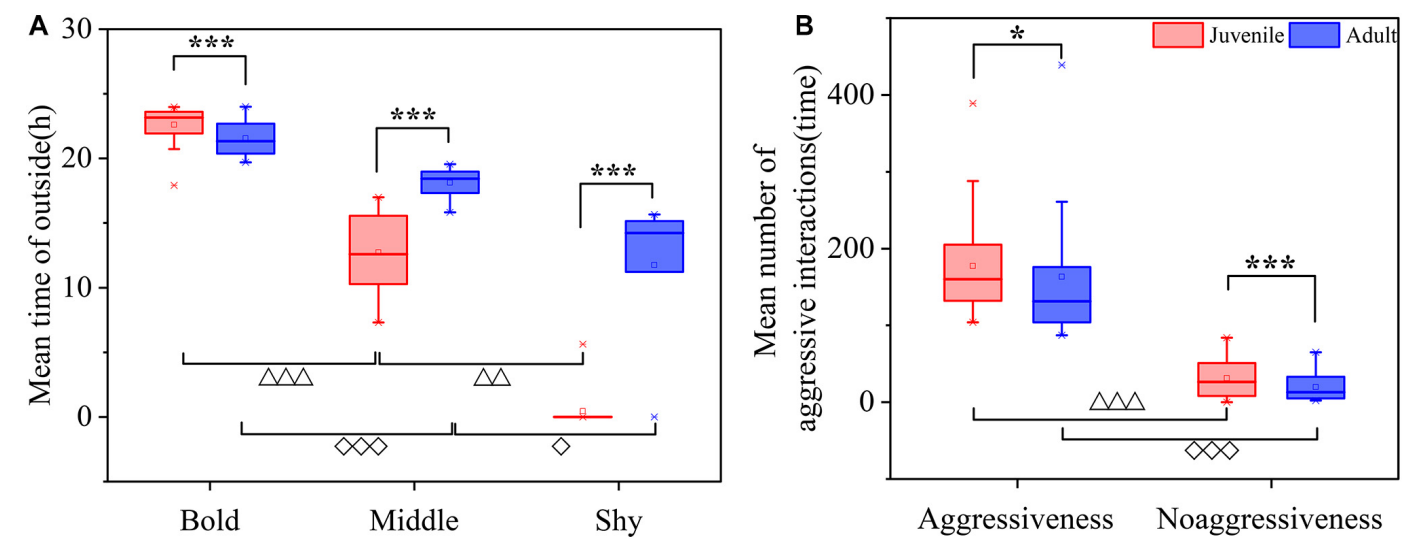

FIGURE 1 | Individual differences between juvenile and adult crabs at different levels. (A) boldness difference. (B) Aggressiveness difference. Asterisk represents that individual difference between juvenile and adult crabs at the same level (“*”: $P<0.05$; "***”: $P<0.001$ ). Triangle represents that individual difference between different levels of juvenile crabs (" $\Delta \Delta$ ": $P<0.01$; " $\Delta \Delta \Delta$ ": $P<0.001$ ). Rhombus represents individual difference between the different levels of personality of adult crabs (" $\diamond$ ": $P<0.05$; " $\diamond \diamond \diamond$ ": $P<0.001$ ).

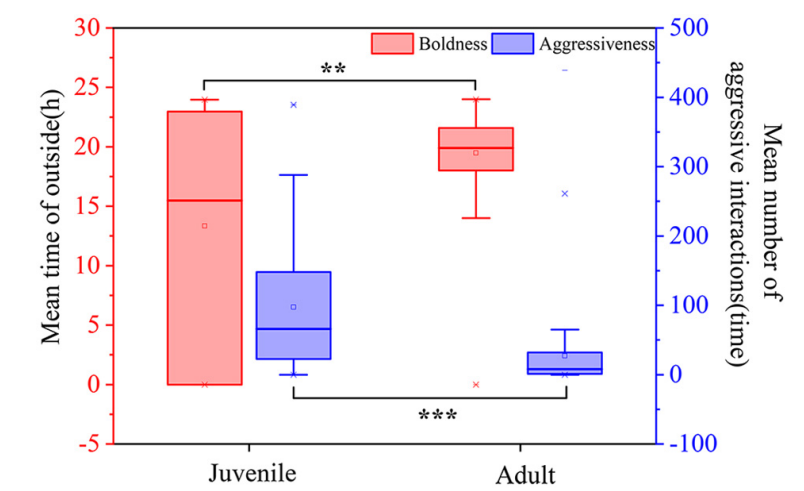

FIGURE 2 | Personality differences between juvenile and adult crabs. The left $Y$-axis represents the boldness of the crabs; the right $Y$-axis represents the aggressiveness. "**” indicated that there was a significant difference in boldness between juvenile and adult crabs, $P<0.01$, and "***" indicated that there was an extremely significant difference in aggressiveness between juvenile and adult crabs, $P<0.001$.
$P$. trituberculatus males regarding the mean number of aggressive interactions (Figure 1B). Moreover, juvenile crabs were significantly more aggressive than adult crabs $(P<0.001$, Figure 2). This result indicates that $P$. trituberculatus males was more aggressive in its juvenile stage. The proportion of aggressive juvenile and adult crabs was approximately 45 and 9\%, respectively. Juvenile crabs were fivefold more aggressive than adults, indicating that $P$. trituberculatus males not only had a higher mean aggressiveness but also
TABLE 2 | Correlation and dispersion between the boldness and aggressiveness of juvenile and adult crabs.

\begin{tabular}{llrcc}
\hline & Personality & IQR & $\boldsymbol{\rho}$ & $\boldsymbol{P}$ \\
\hline Juvenile & Boldness & 22.99 & 0.042 & 0.702 \\
& Aggression & 126.00 & & \\
Adult & Boldness & 3.64 & $0.271^{\star \star}$ & $\mathbf{0 . 0 0 1}$ \\
& Aggression & 32.00 & & \\
Juvenile $\times$ Adult & Boldness & 6.12 & & \\
& Aggression & 62.00 & -0.030 & 0.662 \\
& &
\end{tabular}

Bold represents a significant correlation. The $\rho$-value is plus indicating a positive correlation between boldness and aggressiveness and the $\rho$-value is minus indicating a negative correlation. ${ }^{* *} /$ ndicates that there is a significant correlation between boldness and aggressiveness at the 0.01 level (double-tailed).

had a greater proportion of aggressive individuals. The IQR of juvenile crabs was approximately fourfold higher than that of adult crabs (Table 2), indicating that the aggressiveness of juvenile crabs was more dispersed than adult crabs (Figures 3A,B).

\section{Behavioral Correlation}

Spearman correlation analysis showed that there was no significant correlation between boldness and aggressiveness in juvenile crabs $(P=0.702, \rho=0.042$, Table 2$)$. However, there was a significant positive correlation between boldness and aggressiveness of adult crabs $(P=0.001, \rho=0.271$, Table 2). Moreover, the Spearman correlation coefficient was positive, indicating that, with the increase in adult crabs' boldness, their aggressiveness also tended to increase. 

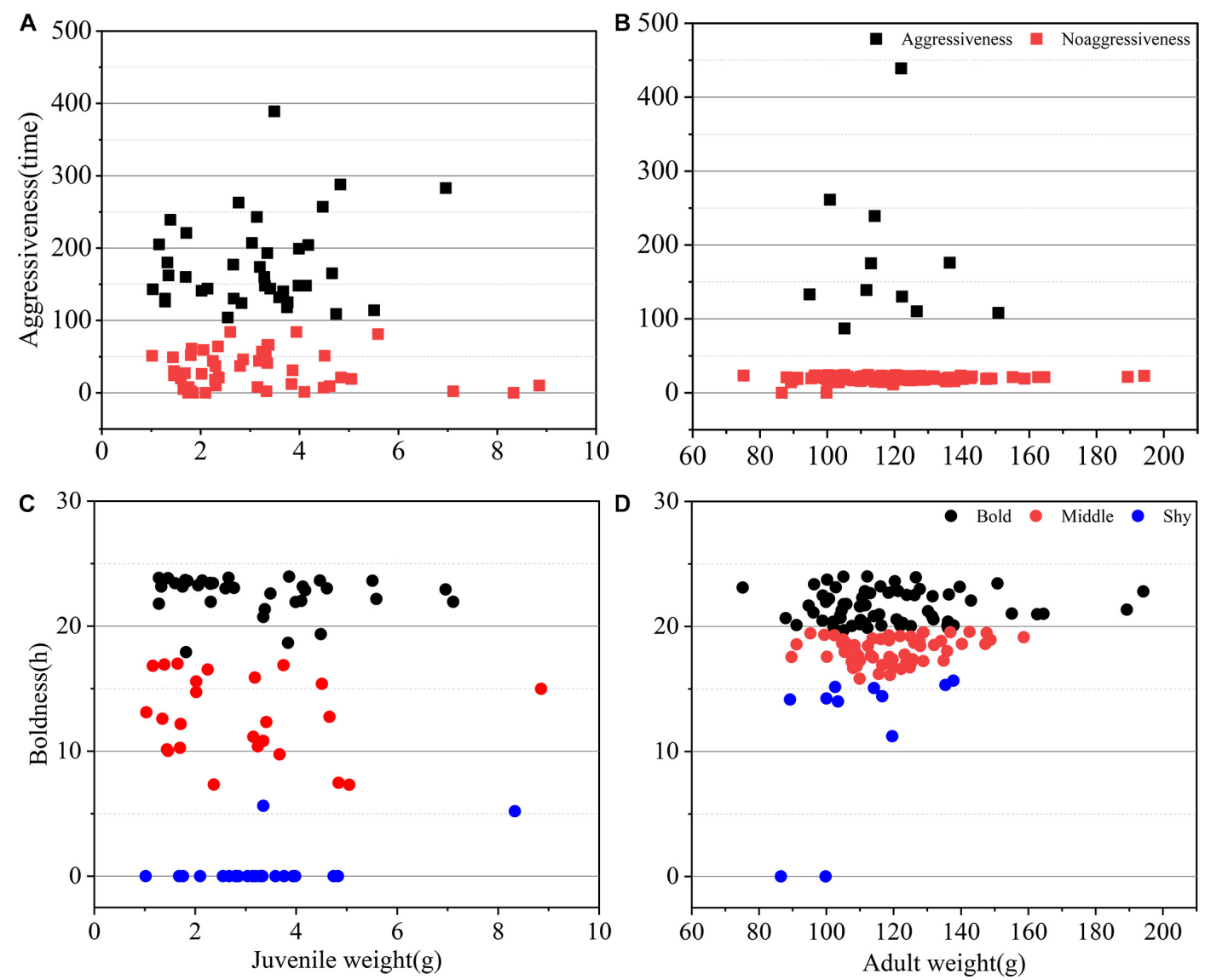

FIGURE 3 | Personality distribution of boldness and aggressiveness in juvenile and adult crabs. (A) Aggressiveness distribution of juvenile crabs and (B) adult crabs. (C) Boldness distribution of juvenile crabs. (D) Adult crabs. Different colors represent different personality levels of crabs. Different shapes represent different personalities, squares represent aggressiveness, and circles represent boldness.

\section{DISCUSSION}

\section{The Effect of Environment Factors}

This study showed that $P$. trituberculatus males had individual differences in behaviors, consistent with the results of a study on the hermit crab (Mowles et al., 2012); during its growth, its personality changed within the population. As expected, with the growth of $P$. trituberculatus males, their boldness was enhanced, and there was a significant positive correlation between boldness and aggressiveness in adult crabs. However, interestingly, their aggressiveness was reduced, and there was no significant correlation between boldness and aggressiveness in juvenile crabs. Our hypotheses were not exactly consistent with the results. Nonetheless, studies have shown that animal personality is usually associated with behavioral phenotypes (van Oers et al., 2005), and that behavioral phenotypes are influenced by the respective situation (Clark and Ehlinger, 1987; Bell and Sih, 2007). Therefore, the variation in animal personality is affected by the respective situation in which the animal finds itself (Bergmuller and Taborsky, 2010; Stamps and Krishnan, 2014). For example, in a constantly stimulating situation (repeated chasing with a net), captured wild fish
(Brachyraphis episcopi) would increase their boldness regardless of the high or low predation risk (Brown et al., 2007). Carere et al. (2005) found that the aggressiveness of adult great tits (Parus major) was affected by food availability during the juvenile period. Interestingly, individuals with adequate food intake during their juvenile period were more aggressive during adulthood. In swimming crabs cultured in ponds, due to the high rearing density, the juvenile crabs were prone to insufficient food supply, leading to intra-species competition and cannibalism. Because the high level of aggressiveness was more beneficial to survival (Johnson and Sih, 2005), juvenile crabs were significantly more aggressive than adults. As individuals grew, density gradually decreased, food and space resources became relatively sufficient, and the aggressiveness of adult crabs decreased. Similar observations have also been found in studies on Gasterosteus aculeatus (Bell and Sih, 2007). Therefore, changes in animal personality during growth may be environmentrelated adaptations.

\section{Growth-Mortality Trade-Offs}

Another reason for the change in animal personality may be the trade-offs between growth and mortality 
(Werner and Anholt, 1993; Stamps, 2007); trade-offs play a crucial role in explaining many ecological and evolutionary patterns (Sih et al., 2004a). During the growth process, animals often face growth-mortality trade-offs (van Oers et al., 2005). If the expected benefit is sufficiently large, then the individual can choose to take risks, and the optimal degree of risk depends on the context. Individuals should choose behaviors that are beneficial under a specific situation (Wilson, 1998; Sih et al., 2004a,b). In this study, we verified that juvenile crabs grew faster than adult crabs (Wang et al., 2018). Individuals' choice of high growth rate would increase the average level of aggressive behavior in the population (Stamps, 2007). Therefore, juvenile crabs were significantly more aggressive than adult crabs (Figure 2). Individuals who attempted to sustain a high growth rate might have been consistently more at risk in foraging environments than individuals who aimed to sustain a lower growth rate (Sih et al., 2003); bold and aggressive individuals may have a lower lifespan (Wolf et al., 2007). Hence, higher aggressiveness leads to higher mortality of juvenile crabs.

Kiesel et al. (2012) studied different species of zebrafish (Danios) and found that the most aggressive pearl zebrafish (Danio albolineatus) was not boldest; likewise, the wild-type zebrafish (D. rerio) had the highest boldness and the lowest aggressiveness. The swimming crabs in the present study also showed a similar pattern. The juvenile crabs were less bold but more aggressive, and adult crabs were less aggressive but bolder (Figure 2). Boldness, aggressiveness, and other personality traits of animals are consistent within the individual but are different between individuals (Stamps, 2007). Spatiotemporal changes in environmental conditions and growth-mortality trade-offs have varying effects on the maintenance of different personality types within populations (Cote et al., 2008).

\section{Developmental Plasticity}

Stamps and Krishnan (2014) proposed that variation in animal personality were also related to developmental plasticity over time, aside from external factors such as the environment. For instance, when the mangrove killifish (Kryptolebias marmoratus) was in a low-risk environment, the mean boldness of juveniles increased with age, but the shy individuals became bold, while the bold individuals remained relatively bold (Edenbrow and Croft, 2013). In the present study, we verified that, with the growth of crabs, their personality changed, but there were individual differences in the degree of variation. In bold individuals, juvenile crabs are significantly bolder than adults, while in middle and shy individuals, juvenile crabs are significantly shyer than adults (Figure 1). This result also indicates that boldness of adult crabs had increased, and not all individuals had changed their personality, and shy individuals may have a higher degree of variation for the changed individuals (Magnhagen and Staffan, 2005). In addition, the personality distribution of juvenile crabs was relatively dispersed, whereas, in adulthood, the personality distribution was more concentrated (Table 2), indicating that juvenile crabs had high behavioral plasticity. Studies on zebrafish (D. rerio) have shown that aggressive behavior is more susceptible to changes in the early stages of development and is more plastic (Moretz et al., 2007). This was consistent with the results of the present. However, Sih et al. (2004b) proposed that when behavioral traits have potential plasticity throughout life, it is difficult to understand why inter-individual variation and intra-individual stability occur at the same time because high-level behavior plasticity indicates that any individual is able to exhibit the best behavior pattern under given conditions, therefore, in a specific situation, there should not be too many individual differences in behavior. Thus, behavioral plasticity is also limited (Bell, 2007). Many behavioral differences within a population cannot be attributed to plasticity alone, and the developmental process can also exert a significant impact on behavioral correlation across contexts (environmental commonality) and across time (temporal consistency) (Stamps and Groothuis, 2010).

\section{Behavioral Syndrome}

The concept of behavioral syndrome implies limited behavioral plasticity (Sih et al., 2004a). In the life span of an organism, none of these personalities is optimal, but these personalities are part of the optimal life history (Sih et al., 2004b). In the different growth stages of $P$. trituberculatus males, there was no significant correlation between the boldness and aggressiveness of juvenile crabs and no significant correlation in the mixed of juvenile and adult crabs. However, there was a significant positive correlation in adults (Table 2 ). This may be related to the degree of personality dispersion in the population (Cote et al., 2010). The degree of personality dispersion in juvenile crabs was much higher than that in adult crabs (Table 2), which indirectly indicated that juvenile crabs had lower behavioral correlation than adult crabs. The correlation between a certain personality or multiple personalities may be the same or different during individual development (Guenther et al., 2014). According to the adaptive perspective, some studies have suggested that the correlation between behaviors may be due to the fact that specific behavioral traits combine well; that is, the animal personality may be a comprehensive set of behaviors that are the result of selection rather than a constraint on selection (Cheverud, 1996). Huntingford (1976) showed that aggressiveness of G. aculeatus was positively correlated with boldness. In contrast, Bell (2005) studied the "activity-aggressiveness-boldness syndrome" of different populations of $G$. aculeatus and tested correlations between behaviors. On average, boldness and aggressiveness were negatively correlated across populations. Whether the correlation is positive or negative depends on how the variable is defined. If the defined behavior is higher aggressiveness or boldness, leading to greater value, then consistent behavior tendencies will produce a positive correlation and vice versa (Sih et al., 2004b).

For personality, an important evolutionary result is that related behavior traits may not evolve independently and freely. Therefore, the preference for one behavior (e.g., risky behavior) may lead to a completely different behavior (e.g., aggressive behavior) change. In other words, the link between boldness and aggressiveness may constrain evolution because evolution follows the "line of least resistance" (Schluter, 1996). 
In addition, Kortet et al. (2014) showed that juvenile brown trout Salmo trutta had consistent behavioral differences in boldness and that these behavioral traits are partially heritable. In summary, limited behavioral plasticity is related with evolution and is heritable in some species. However, whether the behavior of $P$. trituberculatus is heritable needs further study.

\section{CONCLUSION}

This study documented that $P$. trituberculatus males had behavioral differences among individuals. During development, boldness and aggressiveness were highly plastic, with boldness significantly increased and aggressiveness significantly decreased. Currently, research on personality and plasticity are mainly focused on vertebrates. Therefore, this study is expected to provide a new perspective for personality research on crustaceans. However, animal personality affects fitness in complex, environment-related ways. Hence, further research is needed to study the personality plasticity of crustaceans and identify potential influencing factors.

\section{DATA AVAILABILITY STATEMENT}

The original contributions presented in the study are included in the article, further inquiries can be directed to the corresponding author.

\section{REFERENCES}

Ariyomo, T. O., and Watt, P. J. (2012). The effect of variation in boldness and aggressiveness on the reproductive success of zebrafish. Anim. Behav. 83, 41-46. doi: 10.1016/j.anbehav.2011.10.004

Ballew, N. G., Mittelbach, G. G., and Scribner, K. T. (2017). Fitness consequences of boldness in juvenile and adult largemouth bass. Am. Nat. 189, 396-406. doi: 10.1086/690909

Belgrad, B. A., Karan, J., and Griffen, B. D. (2017). Individual personality associated with interactions between physiological condition and the environment. Anim. Behav. 123, 277-284. doi: 10.1016/j.anbehav.2016.11.008

Bell, A. M. (2005). Behavioural differences between individuals and two populations of stickleback (Gasterosteus aculeatus). J. Evol. Biol. 18, 464-473. doi: 10.1111/j.1420-9101.2004.00817.x

Bell, A. M. (2007). Evolutionary biology: animal personalities. Nature 447, 539-540. doi: $10.1038 / 447539$ a

Bell, A. M., and Sih, A. (2007). Exposure to predation generates personality in threespined sticklebacks (Gasterosteus aculeatus). Ecol. Lett. 10, 828-834. doi: 10.1111/j.1461-0248.2007.01081.x

Bell, A. M., and Stamps, J. A. (2004). Development of behavioural differences between individuals and populations of sticklebacks. Gasterosteus aculeatus. Anim. Behav. 68, 1339-1348. doi: 10.1016/j.anbehav.2004.05.007

Bergmuller, R., and Taborsky, M. (2010). Animal personality due to social niche specialisation. Trends Ecol. Evol. 25, 504-511. doi: 10.1016/j.tree.2010. 06.012

Biro, P. A., and Stamps, J. A. (2008). Are animal personality traits linked to lifehistory productivity? Trends Ecol. Evol. 23, 361-368. doi: 10.1016/j.tree.2008. 04.003

Bridger, D., Bonner, S. J., and Briffa, M. (2015). Individual quality and personality: bolder males are less fecund in the hermit crab Pagurus bernhardus. Proc. Royal Soc. B Biol. Sci. 282:20142492. doi: 10.1098/rspb.2014.2492

Brodin, T., and Drotz, M. K. (2014). Individual variation in dispersal associated behavioral traits of the invasive chinese mitten crab (Eriocheir sinensis. H. Milne

\section{ETHICS STATEMENT}

All procedures were performed under the Regulations of the Administration of Affairs Concerning Experimental Animals of China, as well as the Regulations of the Administration of Affairs Concerning Experimental Animals of Shandong Province.

\section{AUTHOR CONTRIBUTIONS}

QL done the date analysis and manuscript writing. XS helped QL for manuscript writing. $\mathrm{BZ}$ and $\mathrm{MH}$ done the animal collection and maintenance. FW was the major instructor. All authors contributed to the article and approved the submitted version.

\section{FUNDING}

This work was supported by the National Key Research and Development Plan Blue Granary Scientific Innovation (No. 2019YFD0900402) and Postgraduate Independent Research Project (No. 201961023).

\section{ACKNOWLEDGMENTS}

We would like to thank Editage (www.editage.cn) for English language editing.

Edwards, 1854) during initial invasion of lake vanern, sweden. Curr. Zool. 60, 410-416. doi: 10.1093/czoolo/60.3.410

Brown, C., Burgess, F., and Braithwaite, V. A. (2007). Heritable and experiential effects on boldness in a tropical poeciliid. Behav. Ecol. Sociobiol. 62, 237-243. doi: 10.1007/s00265-007-0458-3

Carere, C., Drent, P. J., Koolhaas, J. M., and Groothuis, T. G. G. (2005). Epigenetic effects on personality traits: early food provisioning and sibling competition. Behaviour 142, 1329-1355. doi: 10.1163/156853905774539328

Cheverud, J. M. (1996). Developmental integration and the evolution of pleiotropy. Am. Zool. 36, 44-50. doi: 10.1093/icb/36.1.44

Clark, A. B., and Ehlinger, T. J. (1987). "Pattern and Adaptation in Individual Behavioral Differences," in Perspectives in Ethology, eds P. P. G. Bateson and P. H. Klopfer (Boston: Springer), doi: 10.1007/978-1-4613-1815-6_1

Coleman, K., and Wilson, D. S. (1998). Shyness and boldness in pumpkinseed sunfish: individual differences are context-specific. Anim. Behav. 56, 927-936. doi: 10.1006/anbe.1998.0852

Cote, J., Dreiss, A., and Clobert, J. (2008). Social personality trait and fitness. Proc. Royal Soc. B Biol. Sci. 275, 2851-2858. doi: 10.1098/rspb.2008.0783

Cote, J., Fogarty, S., Weinersmith, K., Brodin, T., and Sih, A. (2010). Personality traits and dispersal tendency in the invasive mosquitofish (Gambusia affinis). Proc. Royal Soc. B Biol. Sci. 277, 1571-1579. doi: 10.1098/rspb.2009.2128

Dingemanse, N. J., Kazem, A. J. N., Reale, D., and Wright, J. (2010). Behavioural reaction norms: animal personality meets individual plasticity. Trends Eco. Evol. 25, 81-89. doi: 10.1016/j.tree.2009.07.013

Dirienzo, N., Pruitt, J. N., and Hedrick, A. V. (2012). Juvenile exposure to acoustic sexual signals from conspecifics alters growth trajectory and an adult personality trait. Anim. Behav. 84, 861-868. doi: 10.1016/j.anbehav.2012.07.007

Dunham, D. W., Tierney, A. J., and Franks, P. (1986). Response to mirrors by a cryptic hermit crab. Pagurus marshi. Biotropica 18, 270-271. doi: 10.2307/ 2388497

Edenbrow, M., and Croft, D. P. (2013). Environmental and genetic effects shape the development of personality traits in the mangrove killifish Kryptolebias marmoratus. Oikos 122, 667-681. doi: 10.1111/j.1600-0706.2012.20556.x 
Fu, C., Fu, S. J., Cao, Z. D., and Yuan, X. Z. (2015). Habitat-specific anti-predator behavior variation among pale chub (Zacco platypus) along a river. Mar. Freshwater Behav. Physiol. 48, 267-278. doi: 10.1080/10236244.2015.1050785

Gerlai, R. (2003). Zebra fish: an uncharted behavior genetic model. Behav. Genet. 33, 461-468. doi: 10.1023/A:1025762314250

Groothuis, T. G., and Carere, C. (2005). Avian personalities: characterization and epigenesis. Neurosci. Biobehav. Rev. 29, 137-150. doi: 10.1016/j.neubiorev.2004. 06.010

Guenther, A., Finkemeier, M. A., and Trillmich, F. (2014). The ontogeny of personality in the wild guinea pig. Anim. Behav. 90, 131-139. doi: 10.1016/j. anbehav.2014.01.032

Huntingford, F. A. (1976). The relationship between anti-predator behaviour and aggression among conspecifics in the three-spined stickleback. Gasterosteus Aculeatus. Anim. Behav. 24, 245-260. doi: 10.1016/S0003-3472(76)80034-6

Johnson, J. C., and Sih, A. (2005). Precopulatory sexual cannibalism in fishing spiders (Dolomedes triton): a role for behavioral syndromes. Behav. Ecol. Sociobiol. 58, 390-396. doi: 10.1007/s00265-005-0943-5

Kiesel, A. L., Snekser, J. L., Ruhl, N., and Mcrobert, S. P. (2012). Behavioural syndromes and shoaling: connections between aggression, boldness and social behaviour in three different danios. Behaviour 149, 1155-1175. doi: 10.1163/ 1568539X-00003015

Kortet, R., Vainikka, A., Janhunen, M., Piironen, J., and Hyvarinen, P. (2014). Behavioral variation shows heritability in juvenile brown trout Salmo trutta. Behav. Ecol. Sociobiol. 68, 927-934. doi: 10.1007/s00265-014-1705-z

Magnhagen, C., and Staffan, F. (2005). Is boldness affected by group composition in young-of-the-year perch (Perca fluviatilis)? Behav. Ecol. Sociobiol. 57, 295-303. doi: 10.1007/s00265-004-0834-1

Moretz, J. A., Martins, E. P., and Robison, B. D. (2007). The effects of early and adult social environment on zebrafish (Danio rerio) behavior. Environ. Biol. Fishes. 80, 91-101. doi: 10.1007/s10641-006-9122-4

Mowles, S. L., Cotton, P. A., and Briffa, M. (2012). Consistent crustaceans: the identification of stable behavioural syndromes in hermit crabs. Behav. Ecol. Sociobiol. 66, 1087-1094. doi: 10.1007/s00265-012-1359-7

Norton, W. H. J., and Bally-Cuif, L. (2012). Unravelling the proximate causes of the aggression-boldness behavioural syndrome in zebrafish. Behaviour 149, 1063-1079. doi: 10.1163/1568539X-00003012

Réale, D., Gallant, B. Y., Leblanc, M., and Festa-Bianchet, M. (2000). Consistency of temperament in bighorn ewes and correlates with behaviour and life history. Anim. Behav. 60, 589-597. doi: 10.1006/anbe.2000.1530

Réale, D., Martin, J., Coltman, D. W., Poissant, J., and Festa-Bianchet, M. (2009). Male personality, life-history strategies and reproductive success in a promiscuous mammal. J. Evol. Biol. 22, 1599-1607. doi: 10.1111/j.1420-9101. 2009.01781.x

Réale, D., Reader, S. M., Sol, D., McDougall, P. T., and Dingemanse, N. J. (2007). Integrating animal temperament within ecology and evolution. Biol. Rev. 82, 291-318. doi: 10.1111/j.1469-185X.2007.00010.x

Reaney, L. T., and Backwell, P. R. Y. (2007). Risk-taking behavior predicts aggression and mating success in a fiddler crab. Behav. Ecol. 18, 521-525. doi: 10.1093/beheco/arm014

Schluter, D. (1996). Adaptive radiation along genetic lines of least resistance. Evolution 50, 1766-1774. doi: 10.1111/j.1558-5646.1996.tb03563.x

Sih, A., Bell, A., and Johnson, J. C. (2004a). Behavioral syndromes: an ecological and evolutionary overview. Trends Ecol. Evol. 19, 372-378. doi: 10.1016/j.tree. 2004.04.009

Sih, A., Bell, A. M., Johnson, J. C., and Ziemba, R. E. (2004b). Behavioral syndromes: an integrative overview. Q. Rev. Biol. 79, 241-277. doi: 10.1086/ 422893

Sih, A., Kats, L. B., and Maurer, E. F. (2003). Behavioural correlations across situations and the evolution of antipredator behaviour in a sunfish-salamander system. Anim. Behav. 65, 29-44. doi: 10.1006/anbe.2002.2025

Sih, A., and Watters, J. V. (2005). The mix matters: behavioural types and group dynamics in water striders. Behaviour 142, 1417-1431. doi: 10.1163/ 156853905774539454

Sinn, D. L., Gosling, S. D., and Moltschaniwskyj, N. A. (2008). Development of shy/bold behaviour in squid: context-specific phenotypes associated with developmental plasticity. Anim. Behav. 75, 433-442. doi: 10.1016/j.anbehav. 2007.05.008

Stamps, J., and Groothuis, T. G. G. (2010). The development of animal personality: relevance, concepts and perspectives. Biol. Rev. 85, 301-325. doi: 10.1111/j. 1469-185X.2009.00103.x

Stamps, J. A. (2007). Growth-mortality tradeoffs and 'personality traits' in animals. Ecol. Lett. 10, 355-363. doi: 10.1111/j.1461-0248.2007.01034.x

Stamps, J. A., and Krishnan, V. V. (2014). Individual differences in the potential and realized developmental plasticity of personality traits. Front. Ecol. Evol. 2:69. doi: 10.3389/fevo.2014.00069

Su, X. P., Sun, Y. F., Liu, D. P., Wang, F., Liu, J. J., and Zhu, B. S. (2019). Agonistic behaviour and energy metabolism of bold and shy swimming crab portunus trituberculatus. J. Exp. Biol. 222:jeb188706. doi: 10.1242/jeb.188706

Toscano, B. J., Gatto, J., and Griffen, B. D. (2013). Effect of predation threat on repeatability of individual crab behavior revealed by mark-recapture. Behav. Ecol. Sociobiol. 68, 519-527. doi: 10.1007/s00265-013-1666-7

Vainikka, A., Rantala, M. J., Niemela, P., Hirvonen, H., and Kortet, R. (2011). Boldness as a consistent personality trait in the noble crayfish. Astacus astacus. Acta Ethol. 14, 17-25. doi: 10.1007/s10211-010-0086-1

van Oers, K., Klunder, M., and Drent, P. J. (2005). Context dependence of personalities: risk-taking behavior in a social and a nonsocial situation. Behav. Ecol. 16, 716-723. doi: 10.1093/beheco/ari045

Vetter, S. G., Brandstätter, C., Macheiner, M., Suchentrunk, F., Gerritsmann, H., and Bieber, C. (2016). Shy is sometimes better: personality and juvenile body mass affect adult reproductive success in wild boars. sus scrofa. Anim. Behav. 115, 193-205. doi: 10.1016/j.anbehav.2016.03.026

Wang, X. G., Wang, Y. B., Ye, T., Lu, W. H., and Zhou, C. Y. (2018). A preliminary analysis of the growth characteristics of portunus trituberculatus. Trans. Oceanol. Limnol. 2, 131-136.

Werner, E. E., and Anholt, B. R. (1993). Ecological consequences of the trade-off between growth and mortality rates mediated by foraging activity. Am. Nat. 142, 242-272. doi: $10.1086 / 285537$

Wilson, A. D. M., and Godin, J.-G. J. (2009). Boldness and behavioral syndromes in the bluegill sunfish. Lepomis macrochirus. Behav. Ecol. 20, 231-237. doi: 10.1093/beheco/arp018

Wilson, A. D. M., and Stevens, E. D. (2005). Consistency in context-specific measures of shyness and boldness in rainbow trout, oncorhynchus mykiss. Ethology 111, 849-862. doi: 10.1111/j.1439-0310.2005.01110.x

Wilson, D. S. (1998). Adaptive individual differences within single populations. Philos. Trans. R Soc. Lond B Biol. Sci. 353, 199-205. doi: 10.1098/rstb.1998.0202

Wilson, D. S., Clark, A. B., Coleman, K., and Dearstyne, T. (1994). Shyness and boldness in humans and other animals. Trends Ecol. Evol. 9, 442-446. doi: 10.1016/0169-5347(94)90134-1

Wolf, M., van Doorn, G. S., Leimar, O., and Weissing, F. J. (2007). Life-history trade-offs favour the evolution of animal personalities. Nature 447, 581-584. doi: 10.1038/nature05835

Yang, C., Su, X. P., Liu, D. P., Guo, Z. W., and Lu, Y. L. (2020). A new method of aquatic animal personality analysis based on machine learning (paml): taking swimming crab portunus trituberculatus as an example. Front. Mar. Sci. 7:32. doi: $10.3389 /$ fmars.2020.00032

Yoshida, M., Nagamine, M., and Uematsu, K. (2005). Comparison of behavioral responses to a novel environment between three teleosts, bluegill lepomis macrochirus, crucian carp carassius langsdorfii, and goldfish carassius auratus. Fisher. Sci. 71, 314-319. doi: 10.1111/j.1444-2906.2005.00966.x

Conflict of Interest: The authors declare that the research was conducted in the absence of any commercial or financial relationships that could be construed as a potential conflict of interest.

Copyright (c) 2020 Liang, Su, Wang, Zhu and He. This is an open-access article distributed under the terms of the Creative Commons Attribution License (CC BY). The use, distribution or reproduction in other forums is permitted, provided the original author(s) and the copyright owner(s) are credited and that the original publication in this journal is cited, in accordance with accepted academic practice. No use, distribution or reproduction is permitted which does not comply with these terms. 